\title{
EDITORIAL
}

\section{Indexed hemodynamic measurements may be inappropriate at body surface area extremes}

\author{
Adam C Adler ${ }^{* 1,2}$, Brian H Nathanson ${ }^{3}$, Karthik Raghunathan 1,2 and William T McGee ${ }^{2,4}$
}

As the epidemic of obesity and morbid obesity [1] spreads and as more obese patients require intensive care, it is important to use appropriately body surface area (BSA) indexed hemodynamic measurements [2]. The idea of adjusting for variation in heights and weights while making comparisons was first described by DuBois and Dubois in 1916. Unfortunately, they derived their widely used formula based on only nine patients, none of whom were morbidly obese. Since then, multiple formulae have been proposed based on larger sample sizes, including those by Mosteller, Haycock, Gehan and George, Boyd, Fujimoto, and Livingston [3]. Only Livingston and colleagues made an explicit effort to include obese patients when deriving a BSA formula.

For normal to moderately obese patients, the various BSA formulae will produce similar values [3]. As weights increase disproportionately relative to heights, interformula variability for BSA calculation becomes clinically significant. Figure 1 shows the various BSA estimates for a hypothetical patient at a constant height of $178 \mathrm{~cm}$ but with variable weight from 100 to $325 \mathrm{~kg}$. We see negligible differences between formulae at $100 \mathrm{~kg}$ but the calculated BSA values diverge as weight increases. This is because each formula is extrapolating to extreme body shapes based on derivations from mostly normal-sized patients. The lower indexed values may trigger a therapeutic intervention that may or may not be appropriate for the patient's true needs.

The best way to treat the morbidly obese critically ill patient is an active area of research. Generally, one does not treat the numbers knowing that BSA formulae are not empirically derived from a morbidly obese population. Livingston found that the DuBois and Dubois equation underestimated BSA by as much as $20 \%$ in obese patients [4], while Verbraecken and colleagues found a smaller but still significant underestimation in

\footnotetext{
*Correspondence: adamcadler@gmail.com

'Department of Anesthesiology, Baystate Medical Center, 759 Chestnut Street, Springfield, MA 01199, USA

Full list of author information is available at the end of the article
}

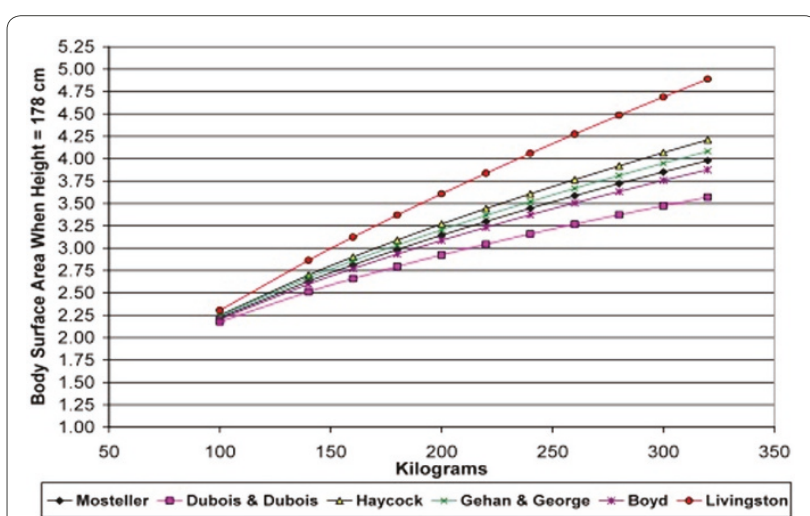

Figure 1. Differences in body surface area by various prediction formulae when height is held constant.

obese patients with this formula. Most hemodynamic monitors such as Vigileo ${ }^{\circ} \mathrm{LiDCO}^{\circ}$ and $\mathrm{PiCCO}^{\circ}$ use the DuBois and DuBois formula to derive BSA, while the $\mathrm{NiCOM}^{\bullet}$ monitor uses the Mosteller formula [5].

We encourage colleagues to be aware of the extent of variation in the derivation of BSA, of the likelihood that the most commonly used formula is not appropriate for use in the morbidly obese patient population and of the fact that indexed measurements reported by typical monitors are not validated in the vulnerable morbidly obese population. We further recommend the use of unindexed values in the very morbidly obese.

\section{Abbreviations}

BSA, body surface area.

\section{Competing interests}

The authors declare that they have no competing interests.

\section{Author details}

'Department of Anesthesiology, Baystate Medical Center, 759 Chestnut Street, Springfield, MA 01 199, USA. ${ }^{2}$ Tufts University School of Medicine, 145 Harrison Avenue, Boston, MA 02111. ${ }^{3}$ OptiStatim, LLC P.O. Box 60844, Longmeadow, MA 01116, USA. ${ }^{4}$ Department of Medicine, Division of Critical Care, Baystate Medical Center, 759 Chestnut Street, Springfield, MA 01199, USA.

\section{Published: 4 September 2012}

\section{References}

1. Berrington de Gonzalez A, Hartge P, Cerhan JR, Flint AJ, Hannan L, Maclnnis RJ, Moore SC, Tobias GS, Anton-Culver H, Freeman LB, Beeson WL, Clipp SL, English DR, Folsom AR, Freedman DM, Giles G, Hakansson N, Henderson KD, 
Hoffman-Bolton J, Hoppin JA, Koenig KL, Lee IM, Linet MS, Park Y, Pocobelli G, Schatzkin A, Sesso HD, Weiderpass E, Willcox BJ, Wolk A, Zeleniuch-Jacquotte A, Willett WC, Thun MJ: Body-mass index and mortality among 1.46 million white adults. N Engl J Med 2010, 363:2211-2219.

2. Westerly BD, Dabbagh O: Morbidity and mortality characteristics of morbidly obese patients admitted to hospital and intensive care units. J Crit Care 2011, 26:180-185.

3. Verbraecken J, Van de Heyning P, De Backer W, Van Gaal L: Body surface area in normal-weight, overweight, and obese adults. A comparison study. Metabolism 2006, 55:515-524.

4. Livingston EH, Lee S: Body surface area prediction in normal-weight and obese patients. Am J Physiol Endrocinol Metab 2001, 281:E586-E591.
5. Cannesson M, Pestel G, Ricks C, Hoeft A, Perel A: Hemodynamic monitoring and management in patients undergoing high risk surgery: a survey among North American and European anesthesiologists. Crit Care 2011, 15:R197.

doi:10.1186/cc11452

Cite this article as: Adler AC, et al:: Indexed hemodynamic measurements may be inappropriate at body surface area extremes [AU Query: Confirm title is OK]. Critical Care 2012, 16:149. 


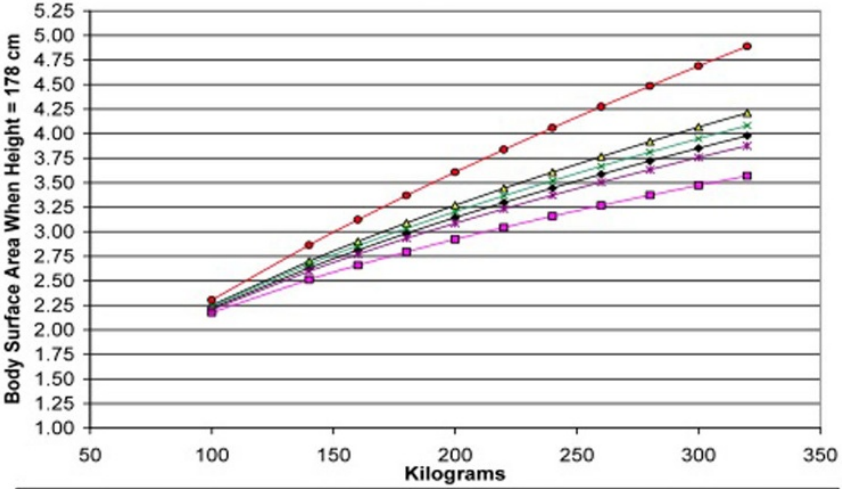

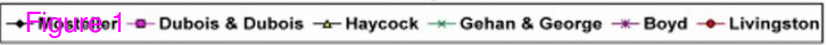

